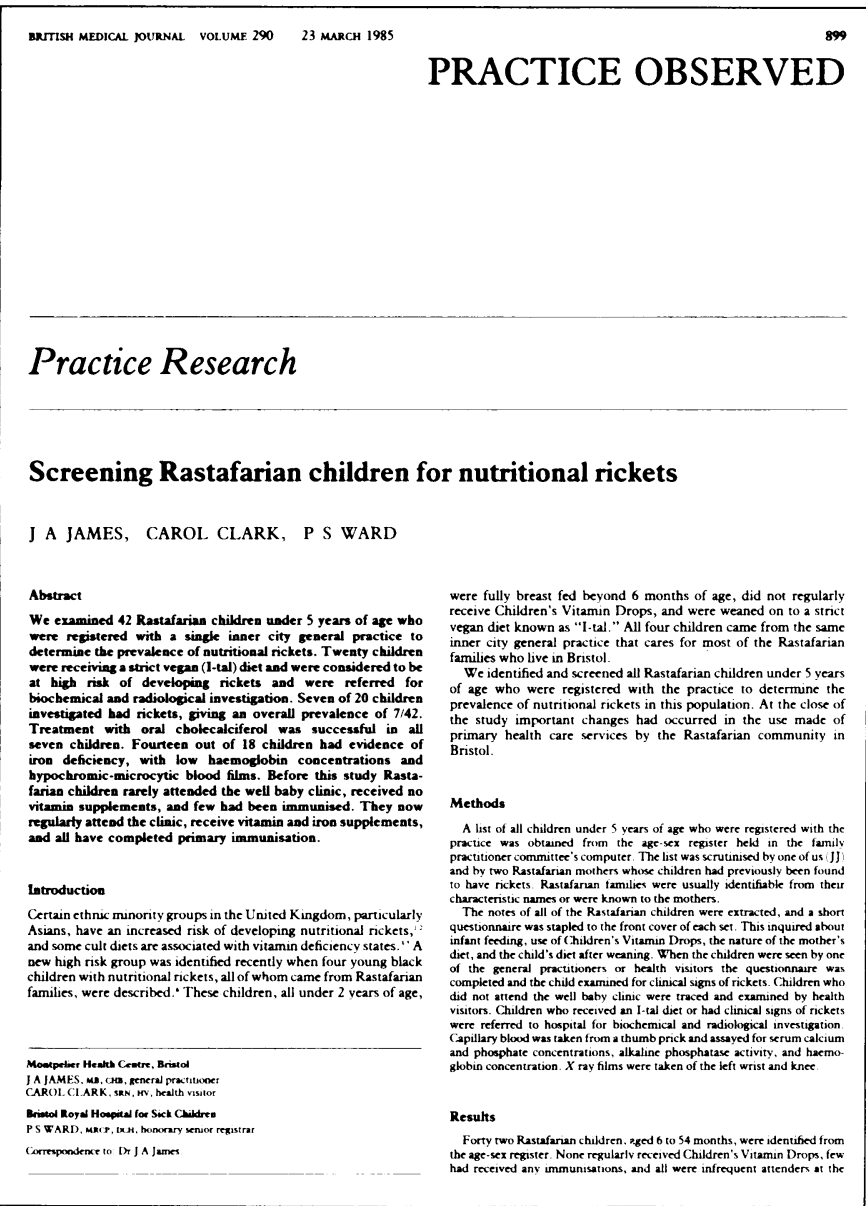

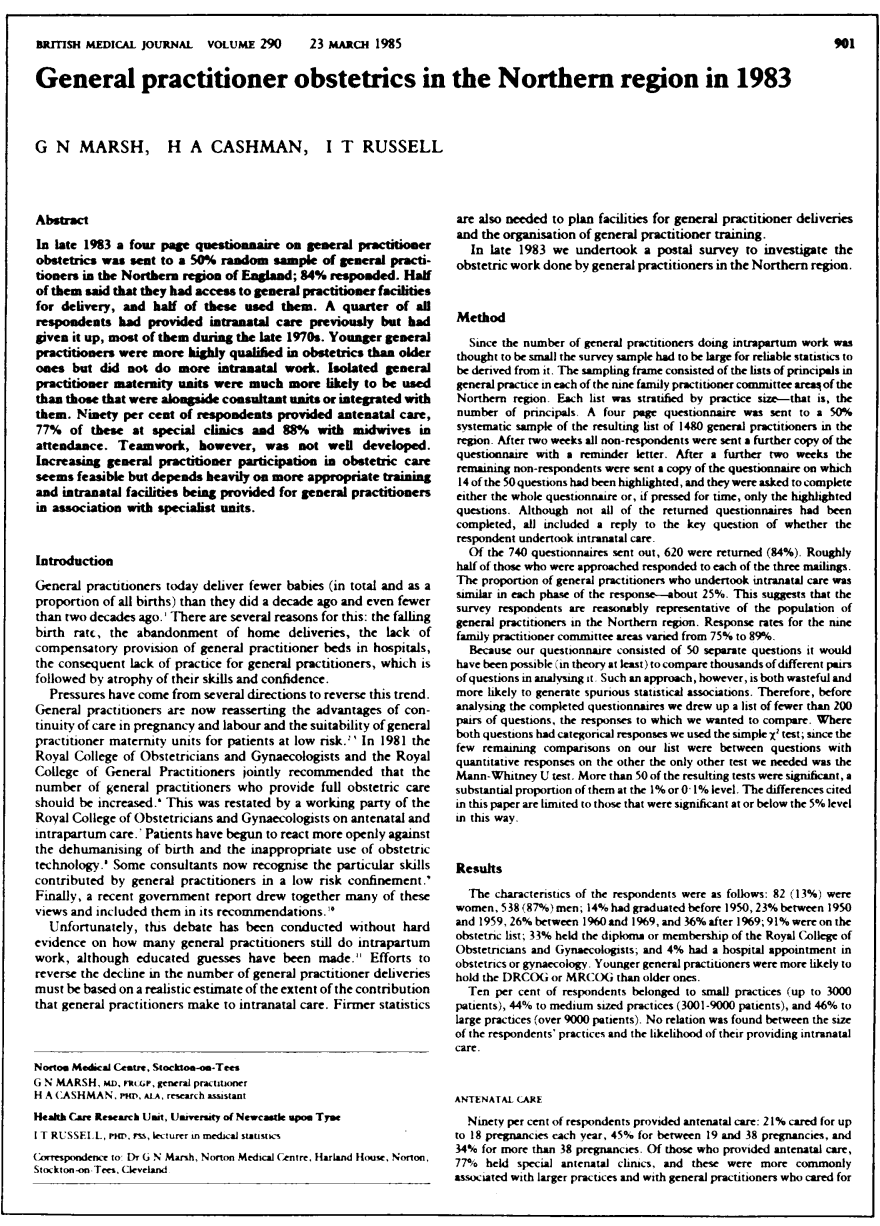
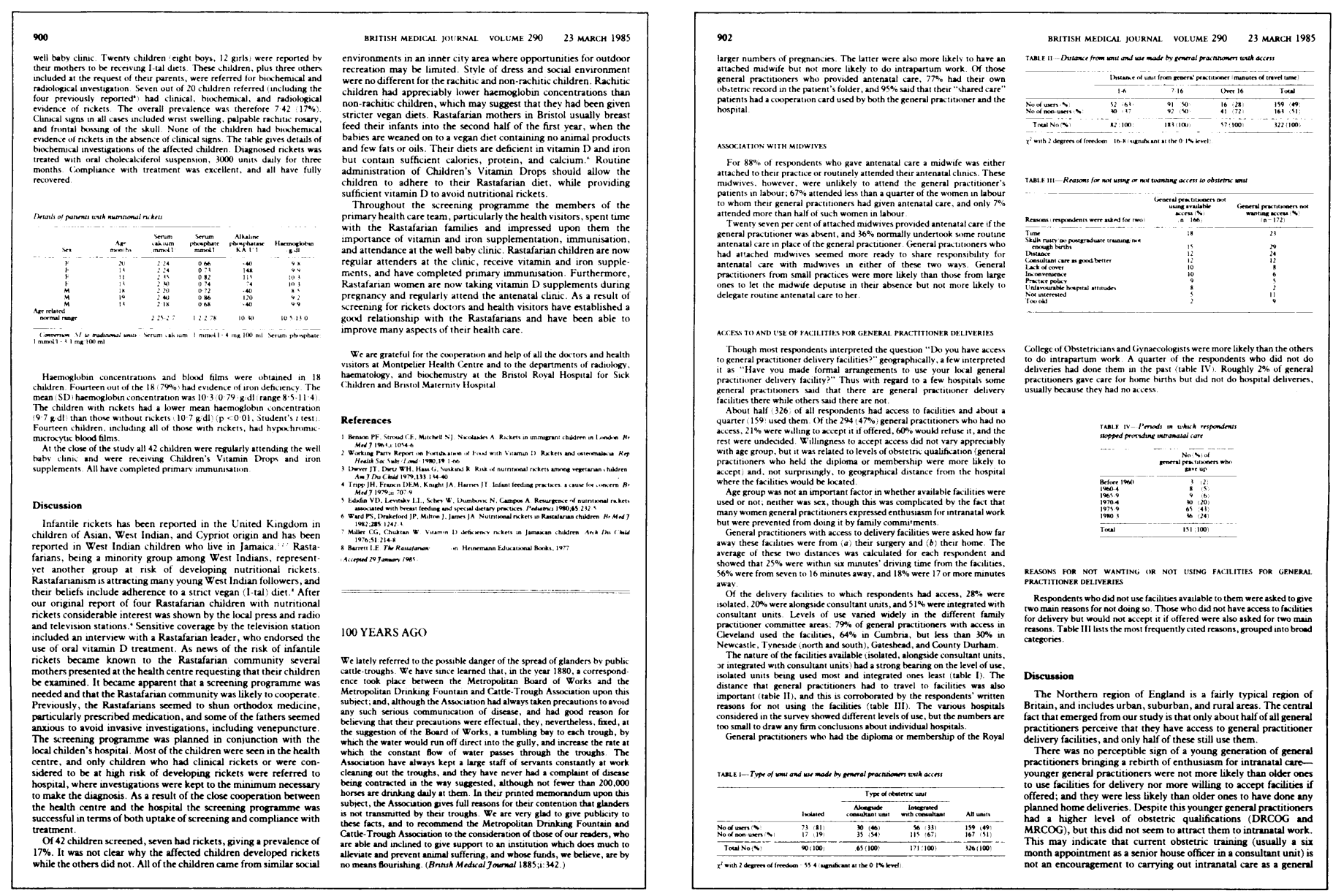


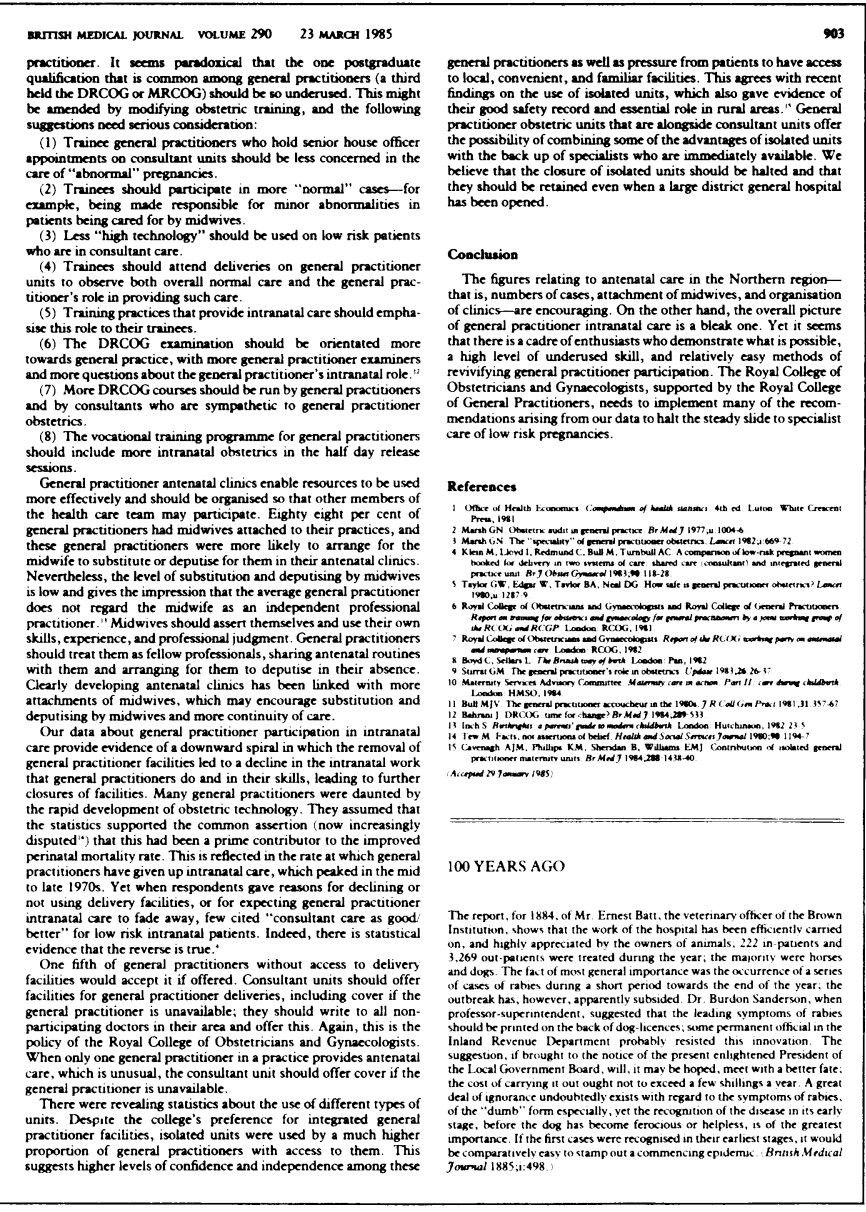

\begin{tabular}{|c|c|c|}
\hline 904 & BRTIISH MERTCAL JOURNAL VOLUME 290 & 23 МАсС 1985 \\
\hline
\end{tabular}

\section{Reconstruction of general practice: the way forward}

F HONIGSBACM

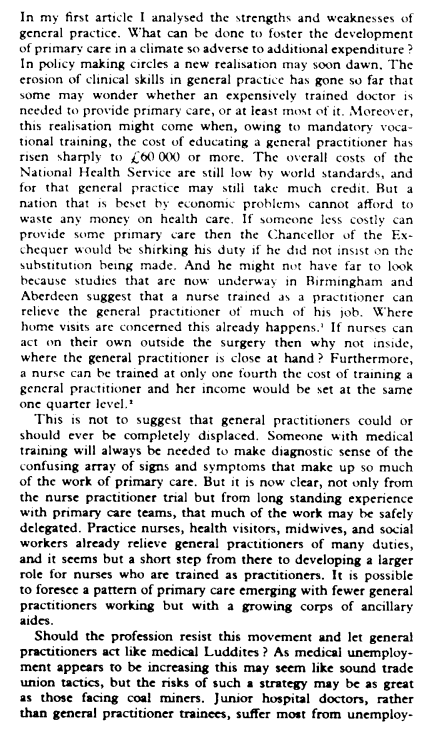

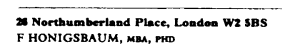

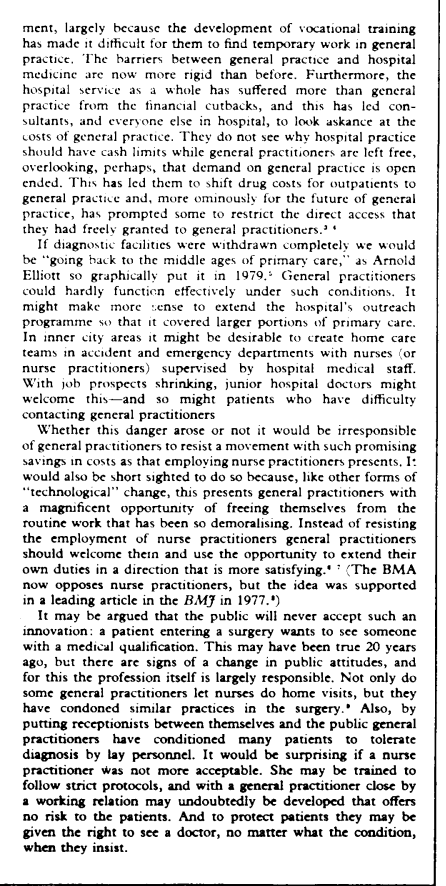

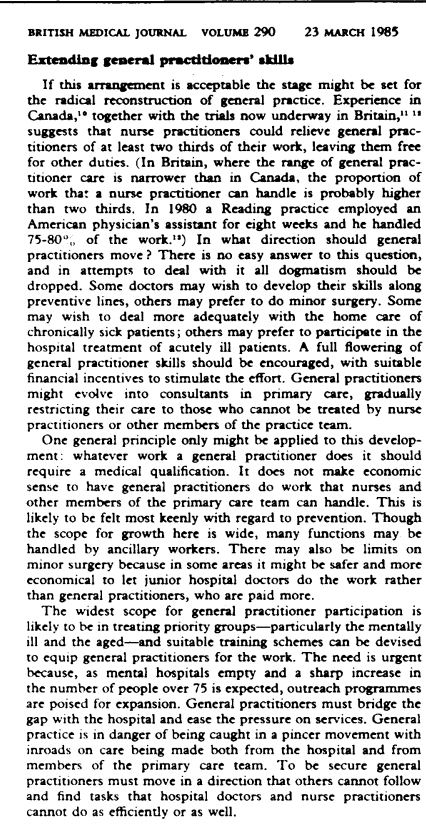

Quality of care

I have deliberately said nothing about the quality of care
becausc the most pressing problem in gencral practice today

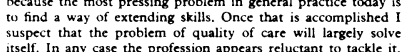
Despite repeated exhortations from leaders of the Royal College
of General
racatitioners, no real progeress has been made with

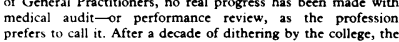

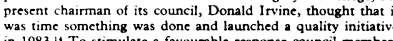

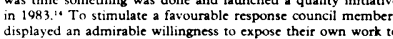

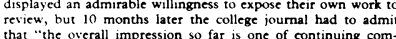

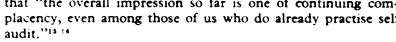
audit.
This failure has dire implications for the future of general
If this reform resulted in longer consultation time then there
is much that might be said for it. Compared with practitioners

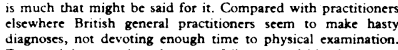

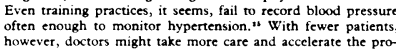
iess of recovery.
There is no guarantee that this would actually happen
of

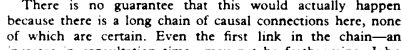
increase in consultation time -may not be fortheoming. - ohn
Butler's pionecring study of the subiect suggesss that the time

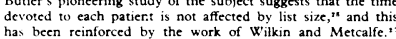

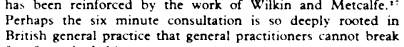

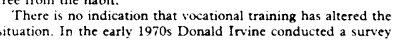

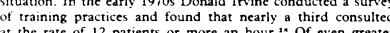

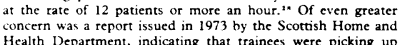

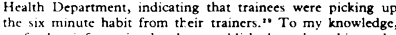

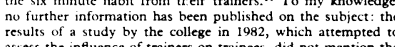

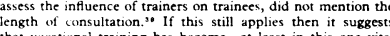

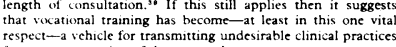

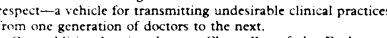
Onc additional point that no Chancellor of the Exchequer
wuld ignore is that the cost of reducing list size would be culd ignore is that the cost of reducing list size would be
enormurust the addition of some 8000 doctors and a cost of

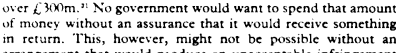

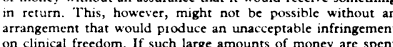
on clinical Irredom. If such large amounts of money are spent
on general practice eit may be betrer to concentrate them at
poinns where the benefirs may be clearly scen.

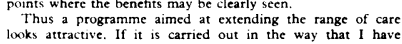

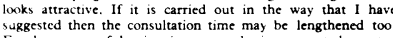

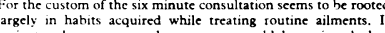

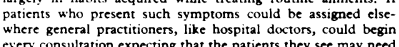

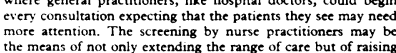
the means of not on
ts quality as well.

\section{Dependence on drug industry}

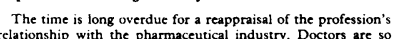

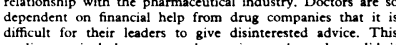

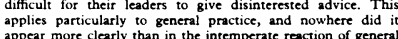

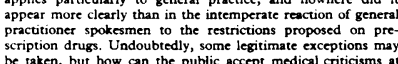

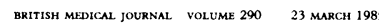

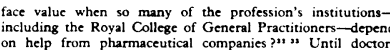

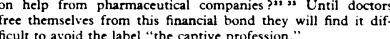
Conclusion

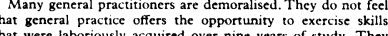
need relief from rovtine work that may be handled adecuarcly

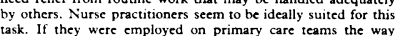

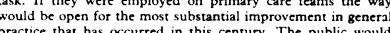
would be open for the most substantial improverement in general
proctice that has oceurred in this sentrury. The public would
benefit enormously from the change. It is hoped that the

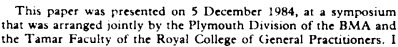

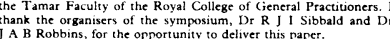

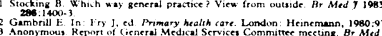

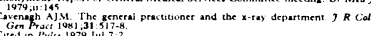

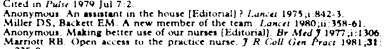

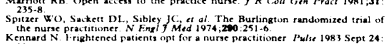

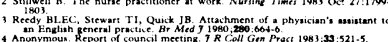

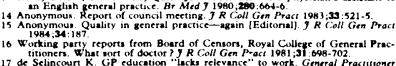

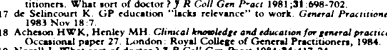

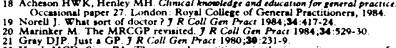

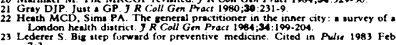

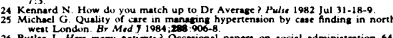

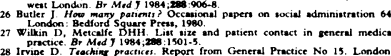

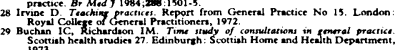

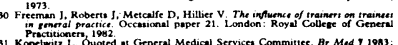

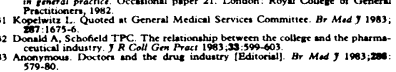

